\title{
Gene polymorphisms associated with non- alcoholic fatty liver disease and coronary artery disease: a concise review
}

\author{
Xiao-Lin Li ${ }^{1}$, Jian-Qing Sui ${ }^{2}$, Lin-Lin Lu ${ }^{3,4}$, Nan-Nan Zhang ${ }^{1}$, Xin X ${ }^{1}$, Quan-Yong Dong ${ }^{1}$, Yong-Ning Xin ${ }^{1,2,3^{*}}$ \\ and Shi-Ying Xuan ${ }^{1,2,3^{*}}$
}

\begin{abstract}
Non-alcoholic fatty liver disease (NAFLD) is a common chronic liver disease which represents a wide spectrum of hepatic damage. Several studies have reported that NAFLD is a strong independent risk factor for coronary artery disease (CAD). And patients with NAFLD are at higher risk and suggested undergoperiodic cardiovascular risk assessment. Cardiovascular disease (CVD) is responsible for the main cause of death in patients with NAFLD, and is mostly influenced by genetic factors. Both NAFLD and CAD are heterogeneous disease. Common pathways involved in the pathogenesis of NAFLD and CAD includes insulin resistance (IR), atherogenic dyslipidemia, subclinical inflammation, oxidative stress, etc. Genomic characteristics of these two diseases have been widely studied, further research about the association of these two diseases draws attention. The gene polymorphisms of adiponectin-encoding gene $(A D I P O Q)$, leptin receptor (LEPR), apolipoprotein C3 (APOC3), peroxisome proliferator-activated receptors (PPAR), sterol regulatory elementbinding proteins (SREBP), transmembrane 6 superfamily member 2 (TM6SF2), microsomal triglyceride transfer protein (MTTP), tumor necrosis factors-alpha (TNF-a) and manganese superoxide dismutase (MnSOD) have been reported to be related to NAFLD and CAD. In this review, we aimed to provide an overview of recent insights into the genetic basis of NAFLD and CAD.
\end{abstract}

Keywords: Non-alcoholic fatty liver disease, Coronary artery disease, Gene pathogenesis, Genetic polymorphisms

\section{Background}

Non-alcoholic fatty liver disease (NAFLD) is recognized as a major public health problem in both developing and developed countries. It is the most common form of liver disease, and represents a wide spectrum of hepatic damage ranging from simple steatosis and non-alcoholic steatohepatitis (NASH) to advanced fibrosis and cirrhosis. NAFLD is recognized as the hepatic manifestation of metabolic syndrome (MS), which major components are insulin resistance (IR), atherogenic dyslipidemia, abdominal obesity, and hypertension [1]. MS is a lethal endocrinopathy involving a chain of systemic disorders such as abdominal obesity, glucose intolerance or diabetes mellitus (DM), dyslipidemia, hypertension and CAD. Nowadays many epidemiological and clinical studies are

\footnotetext{
* Correspondence: xinyongning@163.com; xuansydxy@163.com 'Department of Gastroenterology, Qingdao Municipal Hospital, Dalian Medical University, Qingdao 266011, China
}

Full list of author information is available at the end of the article focused on the association between NAFLD and CAD $[2,3]$. Several studies have reported that NAFLD was a strong independent risk factor for CAD in different racial group and with different research methods [4-6]. Meanwhile, a series of studies showed that in NAFLD patients, CAD was the leading cause of death, among the common causes of death after all of the hepatic and extra hepatic malignancy combined $[7,8]$. Occurrences of these two diseases are both the result of interactions between multiple genetic variations and environmental factors although a full understanding of pathogenesis has not yet been elucidated. Genetic polymorphisms are reported to influence predisposition of individuals to NAFLD and CAD [9, 10]. Moreover, recent progresses in genomics provide new knowledge of both normal and disease states for precision medicine and systems therapeutics. Therefore, this review aim to summarize the recent advances of correlated genes and the promoting mechanism for NAFLD and CAD, and to assess the 
possible implication of these polymorphisms on disease morbidity and severity in those patients. It will aid in the development of genes based therapeutic strategies to combat NAFLD and CAD, and could lead to more effective precision medicine to identify the correct strategies for each individual in order to maximize therapeutic effect and minimize the occurrence of adverse reactions.

\section{Adiponectin-encoding gene (ADIPOQ)}

Adiponectin-encoding gene, $A D I P O Q$, located on chromosome 3q27, encoding adiponectin protein which is an adipocyte-derived hormone with anti-atherogenic, antidiabetic and anti-inflammatory properties. In liver, adiponectin protein attenuates insulin resistance by increasing insulin sensitivity. Besides, adiponectin increases endothelial nitric oxide (NO) secretion and inhibits monocyte adhesion and smooth muscle cell proliferation in the vascular wall $[11,12]$. In NAFLD patients, adiponectin systemic levels is decreased [13]. Adiponectin rs266729 $(-11377 \mathrm{C} / \mathrm{G})$ polymorphism might be a candidate gene, which determines the susceptibility to NAFLD [14]. A study in Indian patients showed an association of two functional polymorphisms, rs266729 and rs2241766 (+45 T/G) of ADIPOQ with the presence and severity of NAFLD, the presence of G allele at position -11377 correlated with necro-inflammatory grade and at position +45 resulted in reduced plasma adiponectin levels in patients suggesting the functional relevance of these polymorphisms in NAFLD pathogenesis and progression [15]. G allele of $r s 266729$ is associated with hypoadiponectinemia, and low serum adiponectin level may precipitate liver steatosis in patients with type 2 diabetes, therefore gene polymorphism of adiponectinrs 266729 is associated with the risk of NAFLD [16]. ADIPOQ expression decreases significantly in epicardial adipose tissue and paracardial adipose tissue in MS patients with CAD [17]. Foucan L. et al. (2010) showed that in AfroCaribbean patients with type 2 diabetes, $r s 2241766$ was associated with CAD under a dominant model [18]. A meta-analysis showed that the associations between $r s 266729, r s 2241766$ and $r s 1501299(+276 \mathrm{G}>\mathrm{T})$ in the $A D I P O Q$ and CVD were significant but weak. The rs2241766 G allele and rs266729 G allele increase risk of CVD, while the rs1501299 $\mathrm{T}$ allele decreases [19]. ADIPOQ rs1501299 is association with CAD, and the SNP has different gender dependent effect on adiponectin levels and the lipoprotein metabolism, considering the detrimental effect that the rare homozygous genotype (TT) was associated with higher levels of total cholesterol (TC) and low density lipoprotein cholesterol (LDL-C) compared to common homozygous genotypes (GG) and heterozygous, and the polymorphism influence on the levels of biochemical markers was independent of adiponectin circulating level [20,21].

\section{Leptin receptor gene (LEPR)}

Leptin exerts its physiological action through the leptin receptor (LepR) which is encoded by a single gene on the chromosome 1p31, leptin receptor gene (LEPR). The polymorphism of LEPR 3057G > A (rs1805096) probably contributes to the onset of NAFLD by regulating lipid metabolism and affecting insulin sensitivity [22]. Lys656Asn (rs8179183) polymorphism of LEPR is associated with insulin resistance and glucose levels in patients with NAFLD [23]. LEPR polymorphism rs1137101, which is responsible for a Gln223Arg change at the protein level is associated with TC, high-density lipoprotein cholesterol (HDL-C) and LDL-C levels in Japanese men [24]. Polymorphisms of LEPR Gln223Arg (G/G) is the risk factors in NAFLD, and the significant interactions between genetic polymorphisms of Gln223Arg added the risk of NAFLD [25]. Gln223Arg polymorphism in the $L E P R$ is associated with an increased risk of familial combined hyperlipidemia which is associated with premature CVD mediated by low HDL-C [26]. LEPR rs1137100 is associated with increased risk of NAFLD and NASH. And it was also associated with simple steatosis and NASH without significant fibrosis [27]. A Japanese study in obese children showed a significantly lower total and LDL cholesterol in subjects with GG genotype [28]. A single nucleotide polymorphism rs 1137100 of LEPR results in Lys109Arg change at the protein level and this has been shown to associate with several risk factors for CVD such as body mass index (BMI), systolic blood pressure (SBP), impaired glucose tolerance and insulin sensitivity [29-31]. In Japanese obese children, the individual with Arg109 is association with serum lipids [28]. Carriers of the Arg109Arg genotype or some other polymorphism linked to it seem to be protective from cardiovascular events as well as from total mortality independently of the traditional CAD risk factors [32].

\section{Apolipoprotein $\mathrm{C} 3$ gene (APOC3)}

Apolipoprotein $\mathrm{C} 3$ gene (APOC3) is located on chromosome 11q23. Apolipoprotein C3 protein is mainly synthesized in the liver and to some extent in the intestine, and it is a component of triglyceride (TG)-rich lipoproteins and HDL. APOC3 gene is involved in transport and clearance of chylomicron remnants, and very-lowdensity lipoprotein (VLDL) and HDL from the bloodstream [33, 34]. A prospective case-control study in the southern Han Chinese population showed that subjects carrying the $\mathrm{C}$ allele (TC or $\mathrm{CC}$ ) of apolipoprotein gene developed insulin resistance (IR) more commonly, and it was in agreement with that found in the Indian population [35]. The polymorphisms $-482 \mathrm{C} / \mathrm{T}$ (rs2854117) and $-455 \mathrm{~T} / \mathrm{C}$ (rs2854116) in APOC3 were associated with NAFLD and IR [35]. The $-455 \mathrm{~T}>\mathrm{C}$ conversion is located in a putative insulin-response 
element of $A P O C 3$, which is associated with plasma TG levels [36-38]. A prospective case-control study involving 300 NAFLD patients and 300 healthy controls indicated that $A P O C 3$ rs 2854116 genetic variations involved in the susceptibility to develop NAFLD, IR, hypertriglyceridemia, and low HDL in the Southern Chinese Han population [39]. A meta-analyses of 20 studies with 15,591 participants found that APOC3 Sst I and rs2854116 polymorphisms might be associated with the risk of CAD [40]. Ding Y. et al.(2012) indicated that the minor alleles of APOC3 $-455 \mathrm{~T} / \mathrm{C}$ polymorphisms were closely associated with acute coronary syndrome, which is a severe type of CAD, and the C allele was associated with higher TG and lower HDL cholesterol [41]. Thus, the $A P O C 3$ might contribute to an increased risk of CAD as a result of its effect on lipid metabolism. Polymorphic variants prevent insulin binding, promoting the transcription and the synthesis of APOC3. As a result, the level of circulating APOC3 increases and acts as alipoprotein lipase inhibitor, leading to decreased clearance of TG-rich particles, which ultimately result in hypertriglyceridemia [42, 43]. The circulating TG-rich particles are preferentially taken up by the liver by means of a receptor-mediated process [44-46], which results in NAFLD and hepatic IR. Whereas a study in the Chinese Han population suggested that the two genetic variants $(\mathrm{T}-455 \mathrm{C}$ at $r s 2854116$ and $\mathrm{C}-482 \mathrm{~T}$ at $r s 2854117$ ) in the $A P O C 3$ were not associated with NAFLD risk, even did not contribute to the interindividual differences in lipid profiles, insulin resistance, obesity, oxidative stress and susceptibility to NAFLD [47]. A case-control study found that the APOC3 3238G allele was significantly associated with increasing plasma TG levels and VLDL-C levels and enhanced risk of CAD via lipid metabolism [48].

\section{Peroxisome proliferator-activated receptors gene (PPAR)}

There are three members of the PPAR family each encoded by a different gene: PPAR (NR1C1), PPAR (NR1C3), and PPAR (NP1C2). Carriers of the PPARY Ala allele showed increased resistance to the development and progression of NAFLD by resisting oxidative stress $[49,50]$. A Meta-analysis demonstrated a protective role for the Ala allele of the PPARY Pro12Ala (rs1801282) polymorphism in NAFLD risk [51], and rs1801282 polymorphism is associated with susceptibility to NAFLD in East Asians, but not in European populations [51]. Domenici F. A. et al. (2013) showed that 12 Ala allele of PPAR $\gamma$ was less prevalent among NASH patients than the healthy volunteers group. There were no associations among PPARY SNPs (rs1801282) and clinical, laboratorial and histological parameters in NAFLD patients, suggest that the SNP rs1801282 may result in protection against liver injury [52]. Leu162Val (rs1800206) PPAR $\alpha$ SNP may be involved in the progression of NAFLD as the carriers have more advanced fibrosis [52]. While Wang J. et al. (2013) suggested that rs1801282 polymorphism of PPARY was not associated with NAFLD risk in both Asian and Caucasian descents from a meta-analysis [53]. A study reported that rs1800206 in PPAR $\alpha$ was significantly associated with Lipoprotein (a) $(\mathrm{Lp}(\mathrm{a}))$ which is a LDL-like particle that can risk atherosclerosis independently and thus is the risk factor of CAD. And provide an evidence PPAR $\alpha / \gamma$ may influence the risk of dyslipidemia and cardiovascular diseases (CVD) via $\operatorname{Lp}(\mathrm{a})[54,55]$. The Ala 12 Ala genotype of the PPAR 2 may decrease the number of diseased vessels and the severity of CAD, which could be because of a direct anti-atherogenic effect of this polymorphism as well as an indirect effect through its association with a lower level of inflammatory parameters and IR [56]. SNP rs3856806 (also termed C161T or $\mathrm{C} 1431 \mathrm{~T}$ ) in the PPAR $y$ was significantly associated with fasted serum lipid profile in individuals with angiographically defined CAD since accumulating data support the role of $P P A R \gamma$ polymorphisms in CAD [57]. Wan J. et al. (2010) indicate that the PPAR r rs3856806 polymorphism may reduce the risk of severe atherogenesis by modulation of adipose metabolism in Chinese patients with CAD [58]. We have previously demonstrated that the SNP rs3856806 was associated with a higher susceptibility to NAFLD through the adiponectin pathway $[59,60]$.

\section{Sterol regulatory elementbinding proteins (SREBPs) / sterol regulatory elementbinding transcription factors (SREBFs) Gene}

Three isoforms of SREBPs are encoded by two genes, SREBP-1 (SREBF-1) and SREBP-2 (SREBF-2). SREBP-1 target genes are involved in cholesterol biosynthesis, unsaturated fatty acid biosynthesis, triglyceride biosynthesis, phospholipid synthesis and lipid uptake [61, 62]. The SREBF-1c rs11868035 polymorphism is associated with increased risk of developing NAFLD with more severe liver histology and derangement in glucose and lipoprotein metabolism, which contribute to the presentation and natural history of NAFLD [63]. SREBP-1c modulates the genetic susceptibility to the whole spectrum of health-related risk in NAFLD by extensively affecting multiple metabolic steps at hepatic and extra-hepatic sites. The SNP rs11868035, which is associated with impaired glucose homeostasis and lipoprotein and adiponectin responses to fat ingestion, was correlated with severity of steatosis and necro-inflammation and the presence of NASH [63]. And associated with CAD risk by modulating the changes in endothelial adhesion molecules $[64,65]$. SREBP-2 encoded by a separate gene on human 
chromosome 22q13, which plays an important role in the maintenance of lipid homeostasis by stimulating the expression of genes correlated with the cholesterol biosynthetic pathways [66, 67]. Activation of the SREBP-2 may play a critical role in enhancing cholesterol uptake and biosynthesis, and can be directly involved in the regulation of cholesterol metabolism in cells, thereby maintaining cholesterol homeostasis [68]. In recent years, some studies have shown that genetic polymorphisms of SREBP-2 have a significant effect on the development of fatty liver disease, IR, and may result in hypertriglyceridemia $[69,70]$. A case-control study in a Han Chinese population provided evidence that the GG genotype and G carrier (CG + GG) of $r s 2228314 \mathrm{G}>\mathrm{C}$ polymorphism in SREBP-2 may increase the risk of NAFLD. Thus, SREBP-2 rs $2228314 \mathrm{G}>\mathrm{C}$ polymorphism may be a potential biomarker for NAFLD [71]. A study from Eastern China manifests that $r s 2228314$ has no association with the risk of premature CAD nor extent of coronary lesions [72]. Further studies are required in this field. The $\mathrm{C}$ allele and the $\mathrm{G} / \mathrm{C}$ genotype of SREBP-2 rs 2228314 were associated with increased risk of NAFLD in Asian Indians. As the G/C genotype of SREBP-2 is significantly associated with Serum levels of TG, elevated CRP, fasting insulin and homeostasis model assessment for insulin resistance levels, it can be a potential explanation for the close relationship between IR, TG, CRP and SREBP-2 polymorphism [73]. The functional SNP $r s 133291 \mathrm{C} / \mathrm{T}$ in the SREBF-2 gene has been linked to serum LDL cholesterol [74]. SREBF-1c SNPs and SREBF-2 SNPs predicted the 7year incidence of NAFLD and diabetes and endothelial dysfunction markers at the end of follow-up in nonobese, nondiabetic, insulin-sensitive subjects without metabolic syndrome at baseline. In biopsy-proven NAFLD patients, SREBF-2 predicted the presence of NASH and extensively affected tissue insulin sensitivity, pancreatic $\beta$-cell function, and lipoprotein and adipokine responses to fat ingestion. The SREBF-1c SNP, which is associated with impaired glucose homeostasis and lipoprotein and adiponectin responses to fat ingestion, was correlated with the severity of steatosis and necro-inflammation and the presence of NASH $[63,64]$.

\section{Transmembrane 6 superfamily member 2 gene (TM6SF2)}

TM6SF2 (rs58542926 c.449 C > T) at the 19 p13.11 locus was associated with hepatic steatosis individuals genotyped using a human exome chip [75]. A exome-wide association studies identified the $r 558542926 \mathrm{C}>\mathrm{T}$ genetic variant of the TM6SF2 gene, which encodes the E167K amino acidic substitution, as a determinant of hepatic TG content, serum aminotransferases, and lower serum lipoproteins $[75,76]$. A case-control study in a community-based Han Chinese population highlight a missense variant in TM6SF2 rs58542926 is significantly contributes to increased NAFLD risk in Chinese population, independent of the Patatin-like phospholipase domain-containing 3 gene $r s 738409$ and neurocan gene rs2228603 polymorphisms, but whether it is also involved in NAFLD disease progression and severity needed further investigation [77]. Dongiovanni P. et al. (2015) suggested that carriers of E167K had a lower prevalence of plaques which is associated with risk factors for atherosclerosis, this protective effect of E167K against carotid atherosclerosis remained significant after adjustment for risk factors and NASH. The carriers have lower serum, and the inhibition of VLDL secretion from the liver protects against CVD, but at the cost of an increased risk of severe liver disease [78]. A mata-analysis showed that although TM6SF2 rs58542926 T allele confers protection against CVD at the expense of higher risk for NAFLD, it does not explain the link between these two complex diseases [79].

\section{Microsomal triglyceride transfer proteingene (MTP/MTTP)}

Act as a key role in lipid metabolism, MTP's functional polymorphisms have previously been investigated. A recent meta-analysis indicates that MTP -493G > T (rs1800591) polymorphisms may contribute to the susceptibility to NAFLD patients. While MTP rs1800591 polymorphism may be a valuable and practical biomarker for early detection of NAFLD [80]. In the Japanese population, a study showed that the- 493 G-allele frequency was significantly higher in patients with biopsy-proven NASH than in the healthy control group, and the GG genotype in NASH patients predicted more severe steatosis [81]. However, the results regarding it are inconsistent. A study in a Brazilian population showed that there was no significant association between the rs1800591 polymorphism and NAFLD [82]. Peng X. E. et al. (2014) showed that MTP rs1800804 $(-164 \mathrm{~T} / \mathrm{C})$ was associated with an increased risk of NAFLD and the level of TG was significantly lower in controls with the rs1800804 (-164 C) risk allele [83]. MTP rs1800804 functional polymorphism and total cholesterol levels have an interaction. Thereby risk allele carriers with low cholesterol levels may be predisposed to an increased risk of developing CVD, which seems to be abolished among risk allele carriers with high cholesterol levels.

\section{Tumor necrosis factors-alpha gene (TNF- $a$ )}

Human TNF- $\alpha$ gene is located on chromosome 6p21.3. The protein it codes acts as a biomarker of systemic inflammation which contributes to IR via multiple direct endocrine and indirect modulatory effects of the genes involved in glucose and lipid metabolism [84, 85], and promotes inflammatory response to injury and regulates 
IR through insulin signal transduction pathways in the liver [86]. Previous studies have shown the association between the TNF- $\alpha$ polymorphisms and the risk of NAFLD, especially in Chinese origin patients. G/A variant at the TNF- $\alpha-238$ increased susceptibility to NAFLD [60]. A study showed that TNF- $\alpha$ G to A polymorphism at position -238 was significantly associated with CAD and that the -238 A allele carriers exhibited an increased risk of developing CAD in Koreans, and therefore this allele could be used as a predictor for CAD in Koreans [87]. However, different ethnicity, phenotype, environment and other factors may have different results [88-91]. Variant at TNF- $\alpha-308$ was notrelevant to NAFLD [60]. However, Hussain S. et al. (2015) showed that TNF- $\alpha-308 \mathrm{G}>\mathrm{A}$ polymorphism is significantly associated with CAD in the Pakistani population [92]. Recently, Chinese researchers provided preliminary evidence support the association between presence of a TNF- $\alpha-238$ polymorphism and the developing of CAD in NAFLD patients of Chinese Han origin. They suggested that TNF- $\alpha-238$ GA genotype may increase the risk for CAD in NAFLD patients. TNF- $\alpha-308$ GA heterozygote genotype was positively associated with elevated levels of TG in NAFLD patients with CAD. Then obtained the conclusion that TNF- $\alpha-308$ GA genotype plays a crucial role in the development of CAD in NAFLD patients [93].

\section{Manganese superoxide dismutase gene (MnSOD/SOD2)}

Manganese superoxide dismutase (MnSOD) is an important antioxidant enzyme. There are data indicate that low MnSOD in rodent models of NAFLD may contribute to increased oxidative stress, other studies describe raised levels of this enzyme in NAFLD [94-96]. A casecontrol study and a meta-analysis highlight the mutant genotypes of $\mathrm{TC}+\mathrm{CC}$ of C47T (rs4880) polymorphism in SOD2 had a significant effect on the reduced of CAD risk [97]. Takami Y. et al. (2010) showed that systemic MnSOD protein is significantly higher in NASH patients than in steatotic patients and healthy controls [98]. A case-control and intra-familial allele association studies prove the evidence that carriage of the $r s 4880$ polymorphism involved in determining the susceptibility to oxidative stress and fibrogenesis, respectively, have been associated with the severity of liver fibrosis in adults and children with NAFLD [99].

\section{Conclusion}

NAFLD and CAD has been a major public health problem affect millions of individuals worldwide. These two diseases are both recognized as the consequence of a complex interplay between genetics, diet and environment although a full understanding of pathogenesis has not yet been elucidated. Recent studies on the genetic polymorphisms association between NAFLD and CAD may provide a new prospective to the diagnosis, prevention and treatment of these two diseases. The role of genetic screening for NAFLD and CAD, while on the cusp, is still premature, further research are needed to exploring the mechanisms underlying this. In future, treatment would be more individualized and approaching to precision medicine depending on the reveal of these underlying mechanisms.

\section{Competing interests \\ The authors declared that they have no competing interests.}

\section{Authors' contributions}

X-LL drafted and wrote the manuscript; J-QS, L-LL, N-NZ, XX and Q-YD revised the manuscript; $Y-N X$ and $S-Y X$ approved the final version. All authors read and approved the final manuscript.

\section{Acknowledgements}

This work was supported in part by National Natural Science Foundation of China (No. 81170337/H0304), Qingdao livelihood, science and technology project, China (grant No.14-2-3-17-nsh) and Qingdao key health discipline development fund.

\section{Author details}

${ }^{1}$ Department of Gastroenterology, Qingdao Municipal Hospital, Dalian Medical University, Qingdao 266011, China. ²Department of Gastroenterology, Qingdao Municipal Hospital, Qingdao 266011, China. ${ }^{3}$ Digestive Disease Key Laboratory of Qingdao, Qingdao 266071, China. ${ }^{4}$ Central Laboratories, Qingdao Municipal Hospital, Qingdao 266071, China.

Received: 9 February 2016 Accepted: 4 March 2016

Published online: 10 March 2016

References

1. Alberti KG, Eckel RH, Grundy SM, Zimmet PZ, Cleeman Jl, Donato KA, et al. Harmonizing the metabolic syndrome: a joint interim statement of the international diabetes federation task force on epidemiology and prevention; national heart, lung, and blood institute; american heart association; world heart federation; international atherosclerosis society; and international association for the study of obesity. Circulation. 2009;120(16):1640-5. doi:10.1161/CIRCULATIONAHA.109.192644.

2. Ampuero J, Gallego-Duran R, Romero-Gomez M. Association of NAFLD with subclinical atherosclerosis and coronary-artery disease: meta-analysis. Revista Espanola Enfermedades Digest Organo Oficial Sociedad Espanola de Patologia Digestiva. 2015;107(1):10-6.

3. Vilar CP, Cotrim HP, Florentino GS, Bragagnoli G, Schwingel PA, Barreto CP. Nonalcoholic fatty liver disease in patients with coronary disease from a Brazil northeast area. Arq Gastroenterol. 2015;52(2):111-6. doi:10.1590/S000428032015000200007.

4. Choi DH, Lee SJ, Kang CD, Park MO, Choi DW, Kim TS, et al. Nonalcoholic fatty liver disease is associated with coronary artery disease in Koreans. World J Gastroenterol WJG. 2013;19(38):6453-7. doi:10.3748/wjg.v19.i38.6453.

5. Kim D, Choi SY, Park EH, Lee W, Kang JH, Kim W, et al. Nonalcoholic fatty liver disease is associated with coronary artery calcification. Hepatology. 2012;56(2):605-13. doi:10.1002/hep.25593.

6. Chiang $\mathrm{CH}$, Huang CC, Chan WL, Chen JW, Leu HB. The severity of non-alcoholic fatty liver disease correlates with high sensitivity C-reactive protein value and is independently associated with increased cardiovascular risk in healthy population. Clin Biochem. 2010;43(18):1399-404. doi:10.1016/j. clinbiochem.2010.09.003.

7. Ong JP, Pitts A, Younossi ZM. Increased overall mortality and liver-related mortality in non-alcoholic fatty liver disease. J Hepatol. 2008;49(4):608-12. doi:10.1016/j.jhep.2008.06.018.

8. Soderberg C, Stal P, Askling J, Glaumann H, Lindberg G, Marmur J, et al. Decreased survival of subjects with elevated liver function tests during a 28-year follow-up. Hepatology. 2010;51(2):595-602. doi:10.1002/hep.23314. 
9. Than NN, Newsome PN. A concise review of non-alcoholic fatty liver disease. Atherosclerosis. 2015;239(1):192-202. doi:10.1016/j.atherosclerosis.2015.01.001.

10. Farrell GC, Wong WW, Chitturi S. NAFLD in Asia-as common and important as in the West. Nat Rev Gastroenterol Hepatol. 2013;10(5):307-18. doi:10.1038/nrgastro.2013.34.

11. Diez JJ, Iglesias P. The role of the novel adipocyte-derived hormone adiponectin in human disease. Eur J Endocrinol / Eur Federation Endocrine Soci. 2003;148(3):293-300.

12. Chandran M, Phillips SA, Ciaraldi T, Henry RR. Adiponectin: more than just another fat cell hormone? Diabetes Care. 2003;26(8):2442-50.

13. Buechler C, Wanninger J, Neumeier M. Adiponectin, a key adipokine in obesity related liver diseases. World J Gastroenterol WJG. 2011;17(23):2801-11. doi:10.3748/wjg.v17.i23.2801.

14. Hashemi M, Hanafi Bojd H, Eskandari Nasab E, Bahari A, Hashemzehi NA, Shafieipour S, et al. Association of Adiponectin rs1501299 and rs266729 Gene Polymorphisms With Nonalcoholic Fatty Liver Disease. Hepat Mon. 2013;13(5):e9527. doi:10.5812/hepatmon.9527.

15. Gupta AC, Misra R, Sakhuja P, Singh Y, Basir SF, Sarin SK. Association of adiponectin gene functional polymorphisms ( $-11377 \mathrm{C} / \mathrm{G}$ and $+45 \mathrm{~T} / \mathrm{G})$ with nonalcoholic fatty liver disease. Gene. 2012;496(1):63-7. doi:10.1016/j.gene. 2011.12.023.

16. Hsieh CJ, Wang PW, Hu TH. Association of adiponectin gene polymorphism with nonalcoholic fatty liver disease in Taiwanese patients with type 2 diabetes. PLoS One. 2015;10(6):e0127521. doi:10.1371/journal.pone.0127521.

17. Gormez S, Demirkan A, Atalar F, Caynak B, Erdim R, Sozer V, et al. Adipose tissue gene expression of adiponectin, tumor necrosis factor-alpha and leptin in metabolic syndrome patients with coronary artery disease. Intern Med. 2011;50(8):805-10.

18. Foucan L, Ezourhi N, Maimaitiming S, Hedreville S, Inamo J, Atallah A, et al. Adiponectin multimers and ADIPOQ T45G in coronary artery disease in Caribbean type 2 diabetic subjects of African descent. Obesity. 2010;18(7):1466-8. doi:10.1038/oby.2009.441.

19. Zhang H, Mo X, Hao Y, Gu D. Association between polymorphisms in the adiponectin gene and cardiovascular disease: a meta-analysis. BMC Med Genet. 2012;13:40. doi:10.1186/1471-2350-13-40.

20. Tureck LV, Leite N, Souza RL, da Silva TL, Osiecki AC, Osiecki R, et al. ADIPOQ single nucleotide polymorphism: Association with adiponectin and lipoproteins levels restricted to men. Meta Gene. 2015;5:98-104. doi:10.1016/j.mgene.2015.06.003.

21. Cheung CY, Hui EY, Cheung BM, Woo YC, Xu A, Fong CH, et al. Adiponectin gene variants and the risk of coronary heart disease: a 16-year longitudinal study. Eur J Endocrinol / Eur Federation Endocrine Soci. 2014;171(1):107-15. doi:10.1530/EJE-14-0079.

22. Lu H, Sun J, Sun L, Shu X, Xu Y, Xie D. Polymorphism of human leptin receptor gene is associated with type 2 diabetic patients complicated with non-alcoholic fatty liver disease in China. J Gastroenterol Hepatol. 2009;24(2):228-32. doi:10.1111/j.1440-1746.2008.05544.x.

23. Aller R, De Luis DA, Izaola O, Gonzalez Sagrado M, Conde R, Pacheco D, et al. Lys656Asn polymorphism of leptin receptor, leptin levels and insulin resistance in patients with non alcoholic fatty liver disease. Eur Rev Med Pharmacol Sci. 2012;16(3):335-41.

24. Takahashi-Yasuno A, Masuzaki H, Miyawaki T, Ogawa Y, Matsuoka N, Hayashi $\mathrm{T}$, et al. Leptin receptor polymorphism is associated with serum lipid levels and impairment of cholesterol lowering effect by simvastatin in Japanese men. Diabetes Res Clin Pract. 2003;62(3):169-75.

25. Zhang C, Guo L, Guo X. Interaction of polymorphisms of Leptin receptor gene Gln223Arg, MnSOD9Ala/Nal genes and smoking in nonalcoholic fatty liver disease. Wei Sheng Yan Jiu. 2014;43(5):724-31.

26. van der Vleuten GM, Kluijtmans LA, Hijmans A, Blom HJ, Stalenhoef AF, de Graaf J. The GIn223Arg polymorphism in the leptin receptor is associated with familial combined hyperlipidemia. Int J Obes. 2006;30(6):892-8. doi:10.1038/sj.ijo.0803234.

27. Zain SM, Mohamed Z, Mahadeva S, Cheah PL, Rampal S, Chin KF, et al. Impact of leptin receptor gene variants on risk of non-alcoholic fatty liver disease and its interaction with adiponutrin gene. J Gastroenterol Hepatol. 2013;28(5):873-9. doi:10.1111/jgh.12104.

28. Okada T, Ohzeki T, Nakagawa Y, Sugihara S, Arisaka O. Study Group of Pediatric $\mathrm{O}$ et al. Impact of leptin and leptin-receptor gene polymorphisms on serum lipids in Japanese obese children. Acta Paediatr. 2010;99(8):1213-7. doi:10.1111/j.1651-2227.2010.01778.x.
29. Kilpelainen TO, Lakka TA, Laaksonen DE, Mager U, Salopuro T, Kubaszek A, et al. Interaction of single nucleotide polymorphisms in ADRB2, ADRB3, TNF, IL6, IGF1R, LIPC, LEPR, and GHRL with physical activity on the risk of type 2 diabetes mellitus and changes in characteristics of the metabolic syndrome: the Finnish diabetes prevention study. Metab Clin Exp. 2008;57(3):428-36. doi:10.1016/j.metabol.2007.10.022.

30. Lakka TA, Rankinen T, Weisnagel SJ, Chagnon YC, Lakka HM, Ukkola O, et al. Leptin and leptin receptor gene polymorphisms and changes in glucose homeostasis in response to regular exercise in nondiabetic individuals: the HERITAGE family study. Diabetes. 2004;53(6):1603-8.

31. Rosmond R, Chagnon YC, Holm G, Chagnon M, Perusse L, Lindell K, et al. Hypertension in obesity and the leptin receptor gene locus. J Clin Endocrinol Metabolism. 2000;85(9):3126-31. doi:10.1210/jcem.85.9.6781.

32. Aijala M, Santaniemi M, Bloigu R, Kesaniemi YA, Ukkola O. Leptin receptor Arg109 homozygotes display decreased total mortality as well as lower incidence of cardiovascular disease and related death. Gene. 2014;534(1):88-92. doi:10.1016/j.gene.2013.10.003.

33. Masebe T, Bessong PO, Ndip RN, Meyer D. Genetic variants of APOC3 promoter and HLA-B genes in an HIV infected cohort in northern South Africa: a pilot study. Int J Mol Sci. 2014;15(7):11403-15. doi:10.3390/ ijms150711403.

34. Tarr PE, Taffe P, Bleiber G, Furrer H, Rotger M, Martinez R, et al. Modeling the influence of APOC3, APOE, and TNF polymorphisms on the risk of antiretroviral therapy-associated lipid disorders. J Infect Dis. 2005;191(9):1419-26. doi:10.1086/429295.

35. Petersen KF, Dufour S, Hariri A, Nelson-Williams C, Foo JN, Zhang XM, et al. Apolipoprotein C3 gene variants in nonalcoholic fatty liver disease. N Engl J Med. 2010;362(12):1082-9. doi:10.1056/NEJMoa0907295.

36. Dammerman M, Sandkuijl LA, Halaas JL, Chung W, Breslow JL. An apolipoprotein CIII haplotype protective against hypertriglyceridemia is specified by promoter and 3' untranslated region polymorphisms. Proc Natl Acad Sci U S A. 1993;90(10):4562-6.

37. Guettier JM, Georgopoulos A, Tsai MY, Radha V, Shanthirani S, Deepa R, et al. Polymorphisms in the fatty acid-binding protein 2 and apolipoprotein C-III genes are associated with the metabolic syndrome and dyslipidemia in a South Indian population. J Clin Endocrinol Metab. 2005;90(3):1705-11. doi:10.1210/jc.2004-1338

38. Waterworth DM, Talmud PJ, Humphries SE, Wicks PD, Sagnella GA, Strazzullo P, et al. Variable effects of the APOC3-482C > T variant on insulin, glucose and triglyceride concentrations in different ethnic groups. Diabetologia. 2001;44(2):245-8. doi:10.1007/s001250051607.

39. Li MR, Zhang SH, Chao K, Liao XH, Yao JY, Chen MH, et al. Apolipoprotein C3 $(-455 \mathrm{~T}>\mathrm{C})$ polymorphism confers susceptibility to nonalcoholic fatty liver disease in the Southern Han Chinese population. World J Gastroenterol WJG. 2014:20(38):14010-7. doi:10.3748/wjg.v20.i38.14010.

40. Lin B, Huang Y, Zhang M, Wang J, Wu Y. Association between apolipoprotein C3 Sst I, T-455C, C-482 T and C1100T polymorphisms and risk of coronary heart disease. BMJ Open. 2014;4(1):e004156. doi:10.1136/bmjopen-2013-004156.

41. Ding Y, Zhu MA, Wang ZX, Zhu J, Feng JB, Li DS. Associations of polymorphisms in the apolipoprotein APOA1-C3-A5 gene cluster with acute coronary syndrome. J Biomed Biotechnol. 2012;2012:509420. doi:10.1155/2012/509420.

42. Li WW, Dammerman MM, Smith JD, Metzger S, Breslow JL, Leff T. Common genetic variation in the promoter of the human apo CIII gene abolishes regulation by insulin and may contribute to hypertriglyceridemia. J Clin Invest. 1995;96(6):2601-5. doi:10.1172/JCl118324.

43. Jong MC, Hofker MH, Havekes LM. Role of ApoCs in lipoprotein metabolism: functional differences between ApoC1, ApoC2, and ApoC3. Arterioscler Thromb Vasc Biol. 1999;19(3):472-84.

44. Cooper AD. Role of the liver in the degradation of lipoproteins. Gastroenterology. 1985;88(1 Pt 1):192-205.

45. Windler EE, Greeve J, Daerr WH, Greten $\mathrm{H}$. Binding of rat chylomicrons and their remnants to the hepatic low-density-lipoprotein receptor and its role in remnant removal. Biochem J. 1988;252(2):553-61.

46. Sherrill BC, Dietschy JM. Characterization of the sinusoidal transport process responsible for uptake of chylomicrons by the liver. J Biol Chem. 1978; 253(6):1859-67.

47. Niu TH, Jiang M, Xin YN, Jiang XJ, Lin ZH, Xuan SY. Lack of association between apolipoprotein C3 gene polymorphisms and risk of nonalcoholic fatty liver disease in a Chinese Han population. World J Gastroenterol WJG. 2014;20(13):3655-62. doi:10.3748/wjg.v20.i13.3655. 
48. Cui F, Li K, Li Y, Zhang X, An C. Apolipoprotein C3 genetic polymorphisms are associated with lipids and coronary artery disease in a Chinese population. Lipids Health Dis. 2014;13:170. doi:10.1186/1476-511X-13-170.

49. Dimitrova-Shumkovska J, Veenman L, Ristoski T, Leschiner S, Gavish M. Chronic high fat, high cholesterol supplementation decreases $18 \mathrm{kDa}$ Translocator Protein binding capacity in association with increased oxidative stress in rat liver and aorta. Food Chem Toxicol Int J Published British Ind Biol Res Assoc. 2010;48(3):910-21. doi:10.1016/j.fct.2009.12.032.

50. Thamer C, Haap M, Volk A, Maerker E, Becker R, Bachmann O, et al. Evidence for greater oxidative substrate flexibility in male carriers of the Pro 12 Ala polymorphism in PPARgamma2. Hormone Metab Res Hormon- Stoffwechselforschung = Hormones Metab. 2002;34(3):132-6. doi:10.1055/s-2002-23196.

51. Lee YH, Bae SC, Song GG. Meta-analysis of associations between the peroxisome proliferator-activated receptor-gamma Pro12Ala polymorphism and susceptibility to nonalcoholic fatty liver disease, rheumatoid arthritis, and psoriatic arthritis. Genet Test Mole Biomark. 2014;18(5):341-8. doi:10.1089/gtmb.2013.0503.

52. Domenici FA, Brochado MJ, Martinelli Ade L, Zucoloto S, da Cunha SF, Vannucchi H. Peroxisome proliferator-activated receptors alpha and gamma2 polymorphisms in nonalcoholic fatty liver disease: a study in Brazilian patients. Gene. 2013;529(2):326-31. doi:10.1016/j.gene.2013.06.091.

53. Wang J, Guo X, Wu P, Song J, Ye C, Yu S, et al. Association between the Pro12Ala polymorphism of PPAR-gamma gene and the non-alcoholic fatty liver disease: a meta-analysis. Gene. 2013;528(2):328-34. doi:10.1016/j.gene.2013.07.014.

54. Danesh J, Collins R, Peto R. Lipoprotein(a) and coronary heart disease. Meta-analysis of prospective studies. Circulation. 2000;102(10):1082-5.

55. Xie HJ, Hai B, Wu M, Chen Q, Liu MM, Dong C, et al. Analysis on the association between PPARalpha/gamma polymorphisms and lipoprotein(a) in a Chinese Han population. Mole Genet Genomics MGG. 2014;289(5):981-7. doi:10.1007/s00438-014-0866-9.

56. Youssef SM, Mohamed N, Afef S, Khaldoun BH, Fadoua N, Fadhel NM, et al. A Pro 12 Ala substitution in the PPARgamma2 polymorphism may decrease the number of diseased vessels and the severity of angiographic coronary artery. Coron Artery Dis. 2013;24(5):347-51. doi:10.1097/MCA.0b013e328361a95e.

57. Oladi M, Nohtani M, Avan A, Mirhafez SR, Tajbakhsh A, Ghasemi F, et al. Impact of the C1431T Polymorphism of the Peroxisome Proliferator Activated Receptor-Gamma (PPAR-gamma) Gene on Fasted Serum Lipid Levels in Patients with Coronary Artery Disease. Annals Nutr Metab. 2015;66(2-3):149-54. doi:10.1159/000381358.

58. Wan J, Xiong S, Chao S, Xiao J, Ma Y, Wang J, et al. PPARgamma gene C161T substitution alters lipid profile in Chinese patients with coronary artery disease and type 2 diabetes mellitus. Cardiovasc Diabetol. 2010;9:13. doi:10.1186/1475-2840-9-13.

59. Hui Y, Yu-Yuan L, Yu-Qiang N, Wei-Hong S, Yan-Lei D, Xiao-Bo L, et al. Effect of peroxisome proliferator-activated receptors-gamma and co-activator-1alpha genetic polymorphisms on plasma adiponectin levels and susceptibility of non-alcoholic fatty liver disease in Chinese people. Liver Int Off J Int Assoc Study Liver. 2008;28(3):385-92. doi:10.1111/j.1478-3231.2007.01623.x

60. Zhou YJ, Li YY, Nie YQ, Yang H, Zhan Q, Huang J, et al. Influence of polygenetic polymorphisms on the susceptibility to non-alcoholic fatty liver disease of Chinese people. J Gastroenterol Hepatol. 2010;25(4):772-7. doi:10.1111/j.1440-1746.2009.06144.x.

61. Shimano H. Sterol regulatory element-binding proteins (SREBPs): transcriptional regulators of lipid synthetic genes. Prog Lipid Res. 2001;40(6):439-52

62. Bauer S, Wanninger J, Schmidhofer S, Weigert J, Neumeier M, Dorn C, et al. Sterol regulatory element-binding protein 2 (SREBP2) activation after excess triglyceride storage induces chemerin in hypertrophic adipocytes. Endocrinology. 2011;152(1):26-35. doi:10.1210/en.2010-1157.

63. Musso G, Bo S, Cassader M, De Michieli F, Gambino R. Impact of sterol regulatory element-binding factor-1c polymorphism on incidence of nonalcoholic fatty liver disease and on the severity of liver disease and of glucose and lipid dysmetabolism. Ame J Clin Nutr. 2013;98(4):895-906. doi:10.3945/ajcn.113.063792.

64. Musso G, Cassader M, Bo S, De Michieli F, Gambino R. Sterol regulatory element-binding factor 2 (SREBF-2) predicts 7-year NAFLD incidence and severity of liver disease and lipoprotein and glucose dysmetabolism. Diabetes. 2013;62(4):1109-20. doi:10.2337/db12-0858.

65. Vaidya D, Szklo M, Cushman M, Holvoet P, Polak J, Bahrami H, et al. Association of endothelial and oxidative stress with metabolic syndrome and subclinical atherosclerosis: multi-ethnic study of atherosclerosis. Eur J Clin Nutr. 2011;65(7):818-25. doi:10.1038/ejcn.2011.47.
66. Bommer GT, MacDougald OA. Regulation of lipid homeostasis by the bifunctional SREBF2-miR33a locus. Cell Metab. 2011;13(3):241-7. doi:10.1016/j.cmet.2011.02.004.

67. Hua X, Sakai J, Ho YK, Goldstein JL, Brown MS. Hairpin orientation of sterol regulatory element-binding protein-2 in cell membranes as determined by protease protection. J Biol Chem. 1995;270(49):29422-7.

68. Sato R. Sterol metabolism and SREBP activation. Arch Biochem Biophys. 2010;501 (2):177-81. doi:10.1016/j.abb.2010.06.004.

69. Horie T, Ono K, Horiguchi M, Nishi H, Nakamura T, Nagao K, et al. MicroRNA-33 encoded by an intron of sterol regulatory element-binding protein 2 (Srebp2) regulates HDL in vivo. Proc Natl Acad Sci U S A. 2010;107(40):17321-6. doi:10.1073/pnas.1008499107.

70. Caballero F, Fernandez A, De Lacy AM, Fernandez-Checa JC, Caballeria J, Garcia-Ruiz C. Enhanced free cholesterol, SREBP-2 and StAR expression in human NASH. J Hepatol. 2009;50(4):789-96. doi:10.1016/j.jhep.2008.12.016.

71. Wang Y, Tong J, Chang B, Wang BF, Zhang D, Wang BY. Relationship of SREBP-2 rs2228314 G > C polymorphism with nonalcoholic fatty liver disease in a Han Chinese population. Genetic Testing Mole Biomark. 2014;18(9):653-7. doi:10.1089/gtmb.2014.0116.

72. Chen Z, Ding Z, Ma G, Liu N, Qian Q. Sterol regulatory element-binding transcription factor (SREBF)-2, SREBF cleavage-activating protein (SCAP), and premature coronary artery disease in a Chinese population. Mol Biol Rep. 2011;38(5):2895-901. doi:10.1007/s11033-010-9951-2.

73. Bhatt SP, Nigam P, Misra A, Guleria R, Luthra K, Vaidya M, et al. SREBP-2 $1784 \mathrm{G} / \mathrm{C}$ genotype is associated with non-alcoholic fatty liver disease in north Indians. Dis Markers. 2011;31(6):371-7. doi:10.3233/DMA-2011-0852.

74. Miljkovic I, Yerges-Armstrong LM, Kuller LH, Kuipers AL, Wang X, Kammerer $\mathrm{CM}$, et al. Association analysis of 33 lipoprotein candidate genes in multi-generational families of African ancestry. J Lipid Res. 2010;51(7):1823-31. do::10.1194/jr.M003897.

75. Kozlitina J, Smagris E, Stender S, Nordestgaard BG, Zhou HH, TybjaergHansen A, et al. Exome-wide association study identifies a TM6SF2 variant that confers susceptibility to nonalcoholic fatty liver disease. Nat Genet. 2014:46(4):352-6. doi:10.1038/ng.2901.

76. Holmen OL, Zhang H, Fan Y, Hovelson DH, Schmidt EM, Zhou W, et al. Systematic evaluation of coding variation identifies a candidate causal variant in TM6SF2 influencing total cholesterol and myocardial infarction risk. Nat Genet. 2014;46(4):345-51. doi:10.1038/ng.2926

77. Wang X, Liu Z, Peng Z, Liu W. The TM6SF2 rs58542926 T allele is significantly associated with non-alcoholic fatty liver disease in Chinese. J Hepatol. 2015;62(6):1438-9. doi:10.1016/j.jhep.2015.01.040.

78. Dongiovanni P, Petta S, Maglio C, Fracanzani AL, Pipitone R, Mozzi E, et al. Transmembrane 6 superfamily member 2 gene variant disentangles nonalcoholic steatohepatitis from cardiovascular disease. Hepatology. 2015;61(2):506-14. doi:10.1002/hep.27490.

79. Pirola CJ, Sookoian S. The dual and opposite role of the TM6SF2rs58542926 Variant in Protecting against Cardiovascular Disease and Conferring Risk for Non-alcoholic fatty liver: A meta-analysis. Hepatology. 2015. doi:10.1002/hep.28142.

80. Zheng W, Wang L, Su X, Hu XF. MTP -493G > T polymorphism and susceptibility to nonalcoholic fatty liver disease: a meta-analysis. DNA Cell Biol. 2014;33(6):361-9. doi:10.1089/dna.2013.2238.

81. Bernard S, Touzet S, Personne I, Lapras V, Bondon PJ, Berthezene F, et al. Association between microsomal triglyceride transfer protein gene polymorphism and the biological features of liver steatosis in patients with type II diabetes. Diabetologia. 2000;43(8):995-9. doi:10.1007/s001250051481.

82. Oliveira CP, Stefano JT, Cavaleiro AM, Zanella Fortes MA, Vieira SM, Rodrigues Lima VM, et al. Association of polymorphisms of glutamatecystein ligase and microsomal triglyceride transfer protein genes in non-alcoholic fatty liver disease. J Gastroenterol Hepatol. 2010;25(2):357-61. doi:10.1111/j.1440-1746.2009.06001.x.

83. Peng XE, Wu YL, Lu QQ, Hu ZJ, Lin X. MTTP polymorphisms and susceptibility to non-alcoholic fatty liver disease in a Han Chinese population. Liver Int Off J Int Assoc Study Liver. 2014;34(1):118-28. doi:10.1111/liv.12220.

84. Nishimura F, Iwamoto Y, Mineshiba J, Shimizu A, Soga Y, Murayama Y. Periodontal disease and diabetes mellitus: the role of tumor necrosis factor-alpha in a 2-way relationship. J Periodontol. 2003;74(1):97-102. doi:10.1902/jop.2003.74.1.97.

85. Ruan H, Miles PD, Ladd CM, Ross K, Golub TR, Olefsky JM, et al. Profiling gene transcription in vivo reveals adipose tissue as an immediate target of tumor necrosis factor-alpha: implications for insulin resistance. Diabetes. 2002;51(11):3176-88. 
86. Hotamisligil GS, Peraldi P, Budavari A, Ellis R, White MF, Spiegelman BM. IRS-1-mediated inhibition of insulin receptor tyrosine kinase activity in TNF-alpha- and obesity-induced insulin resistance. Science. 1996;271(5249):665-8.

87. Cho HC, Yu G, Lee MY, Kim HS, Shin DH, Kim YN. TNF-alpha polymorphisms and coronary artery disease: association study in the Korean population. Cytokine. 2013;62(1):104-9. doi:10.1016/j.cyto.2013.02.008.

88. Allen RA, Lee EM, Roberts DH, Park BK, Pirmohamed M. Polymorphisms in the TNF-alpha and TNF-receptor genes in patients with coronary artery disease. Eur J Clin Investig. 2001;31(10):843-51.

89. Keso T, Perola M, Laippala P, Ilveskoski E, Kunnas TA, Mikkelsson J, et al. Polymorphisms within the tumor necrosis factor locus and prevalence of coronary artery disease in middle-aged men. Atherosclerosis. 2001;154(3):691-7.

90. Wang XL, Oosterhof J. Tumour necrosis factor alpha G-308 > A polymorphism and risk for coronary artery disease. Clin Sci. 2000;98(4):435-7.

91. Herrmann SM, Ricard S, Nicaud V, Mallet C, Arveiler D, Evans A, et al. Polymorphisms of the tumour necrosis factor-alpha gene, coronary heart disease and obesity. Eur J Clin Investig. 1998;28(1):59-66.

92. Hussain S, Iqbal T, Javed Q. TNF-alpha-308G > A polymorphism and the risk of familial CAD in a Pakistani population. Hum Immunol. 2015;76(1):13-8. doi:10.1016/j.humimm.2014.12.010.

93. Cheng $Y, A n B$, Jiang $M, X i n Y, X$ uan $S$. Association of tumor necrosis factor-alpha polymorphisms and risk of coronary artery disease in patients with Non-alcoholic fatty liver disease. Hepat Mon. 2015;15(3):e26818. doi:10.5812/hepatmon.26818.

94. Perlemuter G, Davit-Spraul A, Cosson C, Conti M, Bigorgne A, Paradis V, et al. Increase in liver antioxidant enzyme activities in non-alcoholic fatty liver disease. Liver Int Off J Int Assoc Study Liver. 2005;25(5):946-53. doi:10.1111/j.1478-3231.2005.01126.x.

95. Kohjima M, Enjoji M, Higuchi N, Kato M, Kotoh K, Yoshimoto T, et al. Re-evaluation of fatty acid metabolism-related gene expression in nonalcoholic fatty liver disease. Int J Mole Med. 2007;20(3):351-8.

96. Tsuchiya H, Ashla AA, Hoshikawa Y, Matsumi Y, Kanki K, Enjoji M, et al. Iron state in association with retinoid metabolism in non-alcoholic fatty liver disease. Hepatol Res Off J Japan Soc Hepatol. 2010;40(12):1227-38. doi:10.1111/j.1872-034X.2010.00719.x.

97. Tian C, Liu T, Fang S, Du X, Jia C. Association of C47T polymorphism in SOD2 gene with coronary artery disease: a case-control study and a meta-analysis. Mol Biol Rep. 2012;39(5):5269-76. doi:10.1007/s11033-011-1324-y.

98. Takami Y, Uto H, Tamai T, Sato Y, Ishida Y, Morinaga H, et al. Identification of a novel biomarker for oxidative stress induced by hydrogen peroxide in primary human hepatocytes using the 2-nitrobenzenesulfenyl chloride isotope labeling method. Hepatol Res Off J Japan Soc Hepatol. 2010;40(4):438-45. doi:10.1111/j.1872-034X.2009.00615.x.

99. Al-Serri A, Anstee QM, Valenti L, Nobili V, Leathart JB, Dongiovanni P, et al. The SOD2 C47T polymorphism influences NAFLD fibrosis severity: evidence from case-control and intra-familial allele association studies. J Hepatol. 2012;56(2):448-54. doi:10.1016/j.jhep.2011.05.029.

\section{Submit your next manuscript to BioMed Central and we will help you at every step:}

- We accept pre-submission inquiries

- Our selector tool helps you to find the most relevant journal

- We provide round the clock customer support

- Convenient online submission

- Thorough peer review

- Inclusion in PubMed and all major indexing services

- Maximum visibility for your research

Submit your manuscript at www.biomedcentral.com/submit

) Biomed Central 